\title{
Developing Second Language Reading Comprehension through Short Story
}

\author{
Hafiz Ahmad Bilal \\ Department of English, University of Sargodha, Sargodha \\ E-mail: ahmadbilal.uos@gmail.com \\ Abdur Rehman Tariq \\ E-mail: eskapyst@gmail.com \\ Asif Masood (Corresponding author) \\ E-mail: asifahq@gmail.com \\ Ghazala Nasim \\ E-mail: gazalanasim@yahoo.com \\ Anser Iqbal \\ E-mail: anseriqbal@gmail.com
}

Department of English, University of Lahore, Sargodha Campus, Sargodha, Pakistan

Received: August 2, 2013 Accepted: August 19, 2013 Published: August 20, 2013

doi:10.5296/ijele.v1i3.4152 URL: http://dx.doi.org/10.5296/ijele.v1i3.4152

\begin{abstract}
This study will examine the effectiveness of short story on the reading comprehension of the second language learners. The interface and joint association of literature and language education has been the focus of attention to numerous EFL (English as a Foreign Language) investigators, particularly in the twentieth century. With literature as a medium of instruction for foreign language teaching has proved exceedingly handy. Predominantly the unique attributes of short story, i.e., its pithiness, modernism, and diversity render it alluring as well as fascinating to foreign language students along with a worthy source intended for the enhancement of second language reading comprehension. The short story can proffer learners ample lingual, rational, and emotive engagement and enhance their understanding.
\end{abstract}

Keywords: Short story, reading comprehension, EFL 


\section{Introduction}

Learners are required to have command on reading skills sooner and quicker than ever before. Pedagogy ought to be established on meticulous research, support educators with recognition of learning hurdles, and offer assessments and accountability. Research shows that materials of common interest like short story increases reading skills and comprehension.

Al-Bulushi (2011) aptly appends, "Recent developments in teaching foreign languages stress learner-centered approaches. Literature teaching in language classroom has also been influenced by communicative language teaching since it motivates students to continue language study and prepare them for the type of communication they would experience in the target culture. One such approach, which has a growing influence on English as a Foreign language (EFL) literature teaching, is the Reader-Response Theory (RRT)" (p.450).

\subsection{Reading is Fundamental}

Introduced in 1966 by Margaret McNamara, is a phrase that has permeated the American culture. As a nation, it is recognized that all other curricula areas necessitate reading; students who do not master reading skills are commonly unsuccessful in their school endeavors. In order to succeed in school or life, one must be able to read (Feldman, 2002). Teachers are asked to select the correct approach or approaches to successfully teach students to read. Research shows that the teaching of reading is multifaceted and that a combined approach, including all reading components, is most successful (Moats, 1999).

This research suggests that reading comprehension can be positively influenced by literary texts, specifically through the use of the short story. The short story and related materials is reasonably priced and readily available, so it should be studied in order to ensure a wise expenditure of instructional funds.

\subsection{Statement of the Problem}

Academic abilities, in the educational system of Pakistan, are closely linked with proficiency in reading. If a student is good at reading he will make good grades otherwise he will stay low in the order of merit. And unfortunately, most of the students are not very proficient in reading. Their reading is ill conceived, lack momentum and comprehension, which results in clear and disciplined thinking. Textbooks are dull and boring just filled with contrived and emotionless language with no interest or humour at all. They fail to attract student attention and arouse their curiosity. Majority of the texts are meant to enable the students to master some grammar rules with no communicative objective. Slobodina (1995) sums up the situation aptly, "Most students entering our institute after high school are false beginners with no motivation to learn English. There is no way to inspire them to use the traditional, dry-as-dust textbooks filled with her Majesty's grammar" (p.40). The interaction between the teacher and the students is almost absent. In most of the cases teacher dominates the class with no student's participation. The teaching goal is merely rote learning with no practical communications or exchange of ideas. This very fact provoked me to introduce short story, which are interesting, lively and inspiring. Short story will arouse the curiosity in the students and will activate their minds. There will be a lot of inspiration and motivation for them to try 
and hone their reading skills.

\subsection{Assumptions}

In this study, regarding the effect of short story, on the reading comprehension of 8th graders, the following assumptions have been made:

(a) Students have successfully completed seven grades, as evidenced by a review of report cards and student files;

(b) The school has appropriate national curriculum text books for student to benefit from;

(c) The teachers are credentialed and have appropriate training in text book instruction;

(d) The teacher using the short story program has completed both training seminars and is willing to use this program as recommended;

(e) Reading instruction will be in a like manner within the two classes; short story will be the only dissimilar instructional method;

(f) The school administration will be supportive of the research study;

(g) The parents will be agreed to their child's participation in the study;

(h) The Pretest-Posttest scores will be a reliable measure of student achievement;

(j) Students took the complete reading progression in their earlier grades and a Pretest would be conducted to evaluate their present reading knack; and

(k) Students will be willing to participate in the study.

\subsection{Hypothesis}

The hypothesis of this study is that short story has a positive effect on the reading comprehension skills of 8th grade students. The null hypothesis is that short story has no effect on the reading comprehension of 8 th grade students.

\subsection{Objectives of the Research}

The objectives of the research are: -

(a) To develop the reading comprehension through short story.

(b) To arouse the element of curiosity.

(c) To make them more motivated to learn the language skills.

(d) To bring something of the everyday world into the classroom and to remove the monotony of the contrived texts.

(e) To make them feel as the users of the language rather than a mere learners. 
(f) To give them awareness about the usefulness of short story.

(g) To bring a sense, culture and traditions in the classroom.

\subsection{Ethics of the Research}

This research involves people as research subjects, the researcher have to incorporate an ethics statement in research proposal. Such a proclamation is a sign of his wakefulness of the moral deliberations and an agreement to accomplish the fieldwork in accordance with ethical procedures.

In short, the researcher will guarantee:

(a) That he has a suitable training and preparation for conducting the research.

(b) That the rights and wellbeing of the human subjects he will work with are protected.

(c) That he will guard the identities and benefits of those involved.

(d) That he will reassure the confidentiality of the information given to him.

(e) That he will execute his research in accordance with the ethical and professional guidelines as specified in his disciplinary association.

\subsection{Limitations}

(a) The research could be affected by student access to technology at home.

(b) The research could be affected by student access to books/literature at home.

(c) The research could be affected by previous reading skill development.

(d) The research could be affected by student absenteeism.

(e) The research could be affected by transient students.

(f) The research could be affected by teacher attitude toward short story- assisted instruction.

(g) The research could be affected by individual student's test anxiety both on the short story quizzes and tests.

\subsection{Delimitations}

The boundaries of this study are limited to two 8th grade classes at a School in Wah Cantt, Pakistan or at a Pakistan International School in Qatar.

\subsection{Significance of the Study}

Educators struggle with the need to provide the best education for students while prudently spending allocated resources for curriculum implementation. Students are expected to master reading skills at earlier ages than ever before. Inevitability of reading comprehension puts reading skill acquisition at the forefront of education reform. Teachers are expected to use the 
best methods available to teach children to read (Bush, 2001). Researchers are beginning to identify that reading instruction should be a multifaceted approach to ensure all students receive instruction in a way that makes learning meaningful (Moats, 1999). If this approach is the most beneficial to the student, then educators must carefully choose the most appropriate materials to get the job done. Short story, since it supports an individualized learning approach, may prove to be an effective method of contributing to this multifaceted approach. It is very cost-effective, does not need any substantial investment and not the one that needs to be researched before adoption.

\section{Literature Review}

It is an old saying that you have to "read between the lines" to get the most out of anything.

The foremost undertaking of EFL teachers is, to teach students to read. The relationship between a student's ability to read and their success in school is overwhelming.

\subsection{What is Reading?}

To read is to fly: it is to soar to a point of vantage which gives a view over wide terrains of history, human variety, ideas, shared experience and the fruits of many inquiries. The path of a reader is not a runway but more a hack through a forest, with individual twists and turns, entanglements and moments of surprise. (Holden, 2004). Ours is a time of great interest in and concern about reading. Research and experimentation in all fields of initial reading instruction proceed at an ever-increasing pace. Reading comprehension research has a long and rich history. There is much that we can say about both the nature of reading comprehension as a process and about effective reading comprehension instruction.

\subsection{What is Reading Comprehension?}

Reading comprehension is a development in which the reader devises sense, using as the building materials, the message on the printed page, and the information stockpiled in the reader's head. It involves deliberate thinking, in which significance is built by exchanges amid manuscript and person who reads. Reading is comprehension. Comprehension is what reading is all about. Deciphering without comprehension is merely word barking - being capable of articulating a word appropriately without understanding its gist. Efficient comprehenders not only make logic of the text they are reading, they can also utilize the message it holds.

\subsection{Factors Influencing Reading Comprehension}

Scores of factors influence a learner's capacity to comprehend content. These comprise:

- Stimulus/intention/targets/commitment

- lexis/word acquaintance/backdrop understanding

- automaticity of interpreting

- effortless reading

- understanding and use of stratagem employed by efficient readers

- the character of the text itself i.e. difficulty and interest 
- the nature or genre of text e.g., fiction, nonfiction, poetry

- the quantity of reading made

\subsection{Useful Comprehension Stratagem}

Every comprehension Lesson - shared, read-aloud, and guided reading - must spotlight on educating learners to:

- $\quad$ spot their rationale for reading

- foretaste text prior to reading

- formulate forecasts ahead of and during reading

- elicit pertinent background knowledge for reading

- think aloud while reading

- exploit text formation to shore up comprehension

- engender visual representations i.e. making pictures in their heads

- determine the significant thoughts in the text

- abridge what they read

- generate questions concerning text

- handle alien words during reading

- monitor their comprehension during reading

- employ fix-up approach

\subsection{Evaluating Reading Comprehension}

Since comprehension is a rational progression, it can barely be observed and assessed indirectly. We cannot get within a reader's head to monitor comprehension, but we can deduce comprehension strategies or make them extra evident. Reading comprehension can be inferred and assessed through:

- oral or written retellings

- read-alouds and think-alouds

- answering questions

- filling in missing words in a cloze: Is the word defensible?

- the arts/acting out stories through puppet plays

- written responses

- group discussions

- peer and self-assessments 
- questionnaires

- interviews

- audiotapes of children's readings

\subsection{Vocabulary Development and Background Knowledge}

"It is well established that good comprehenders generally have good vocabularies. And beyond that, there is evidence that teaching students vocabulary, in fact, increases their comprehension abilities" (Pressley 2002, 293). Although vocabulary can be taught, most vocabulary words are learned through reading. That is why people who read a great deal generally have large vocabularies.

Prior knowledge affects comprehension. The more one already knows, the more one comprehends, and the more one comprehends, the more one learns new knowledge to enable comprehension of an even broader array of topics and texts (Fielding and Pearson 1994, 62).

\subsection{Efferent and Aesthetic Reading}

Imaginative literature primarily pleases rather than teaches. It is much easier to be pleased than taught, but much harder to know why one is pleased. Beauty is harder to analyze than truth.

Perhaps the best-known theorist to explicate Reader Response, as a pedagogical as well as critical stance, is Louise Rosenblatt, who formulated the "transactional theory" of reading and the distinction between "efferent" (utilitarian) and "aesthetic" reading. Rosenblatt describes "aesthetic reading" as one that engages readers so that they live through the experience and, in so doing, recreates the text. The main aim of the short story-assisted instruction is to accept multiple interpretations to a text rather than just one correct interpretation. If this aim is important for native speakers, it is even more crucial for EFL/ESL students who need the added motivation to read literature in a foreign language. Short story-assisted instruction differs from the other approaches to read literature in a foreign language.

\subsection{Advantages of Short Stories}

Researchers who bring into play the use of short stories to tutor foreign or second language, record plentiful profits of short stories. These comprise psychological, literary, cultural and high level of thinking benefits. Nonetheless, before teachers come across these rewards in added fine points, they are required to keep one gain in mind that all teachers must take benefit of, reinforcement of skills and proficiency.

\subsection{Reinforcement of Skills}

Short stories let educators drill the four skills at every stage of verbal communication expertise. Murdoch (2002) indicates that "short stories can, if selected and exploited appropriately, provide quality text content which will greatly enhance ELT courses for learners at intermediate levels of proficiency" (p. 9). He elucidate why short story ought to be 
exploited to buttress English Language Teaching through debating activities teachers may craft such as scripting and performing out dialogues.

\subsection{Infusing Superior Reasoning}

Though there are abundant profits of short story, superior reasoning is the most thrilling. Intermediate and higher learners may investigate what they study; hence, they begin considering critically when they read short story. Young (1996) argues exploiting of stories to bring in critical thinking to seminary learners. He trusts that "stories have two crucial advantages over traditional content: First, because they are entertaining, students' pervasive apprehension is reduced, and they learn from the beginning that critical thinking is natural, familiar, and sometimes even fun. Second, the stories put issues of critical thinking in an easily remembered context" (p. 90). Howie (1993) concurs on the application of short story to tutor critical thinking. He wisecracks that teachers have the undertaking to assist learners to swell cognitive skills since each one desires to "make judgments, be decisive, come to conclusions, synthesize information, organize, evaluate, predict, and apply knowledge." By reading and writing, students develop their critical thinking skills (p. 24).

\subsection{Teaching Culture}

Short story is handy in teaching culture to Foreign Language learners. Short story conveys the culture of the populace regarding whom the story is portrayed. Through learning regarding the culture, students learn about the olden times as well as modern, along with concerning people's civilization and customs. Culture educates students to understand and respect people's differences. Whilst utilizing storybook manuscripts, teacher should be conscious that the culture of the people for whom the content was depicted ought to be comprehended. Since learners countenance a novel civilization, they become further sensitive to their individual society. They begin evaluating their society to the other society to discern whether there is resemblance or divergence amid the two societies.

\section{Methodology}

The study will employ the Pretest-Posttest Equivalent-Group Design, including a questionnaire for both groups. It is predicted that the short story program will have a positive effect on reading comprehension.

\subsection{Subjects}

The subjects of this study are 20 eighth grade students at a school in Wah Cantt, Pakistan or at a Pakistan International School in Qatar. The school serves a predominately middle class neighborhood. The majority of the students are from the surrounding homes, and apartments. The students are randomly selected from a total students entering eighth grade at the school. Through random assignment, efforts will be made to balance the two groups by background, and academic achievement.

Students in the treatment group will be placed in a class of ten with a credentialed teacher (the researcher himself) who is trained in teaching literary text instruction and the short story program. Students in the control group will be placed in a class of ten with a credentialed 
school teacher. All students in the treatment group will be taught basics of literary texts sufficient to understand short story program. The school will be committed to provide literary texts, and the availability of two classrooms.

\subsection{Instruments Employed}

To serve this purpose, two instruments will be employed in this study: a reading comprehension Pretest-Posttest and a questionnaire. The questionnaire will be used to elicit student's attitudes towards the short story-assisted reading comprehension. The data obtained from the two instruments will be analyzed using descriptive statistics and t- tests.

\subsection{Procedure}

This study will examine the effectiveness of the short story-assisted program on eighth grade students' reading comprehension. This study will begin at the start of the school year and will continue for four weeks. Treatment group will have access to short story reading materials and the control group will use the normal text book prescribed by the school.

A Pretest will be conducted, the scores will be recorded and then the students in both groups will be given thirty minutes of sustained silent reading time each day in addition to their reading instructional time. During sustained silent reading, students in the treatment group will read selected short story and the control group will read text books according to the program. In addition, the time will be given for completion of the quizzes.

The researcher will spend four weeks visiting the school and teaching the short story to the treatment group twice a week. The control group will be taught by one of the school teachers. This will be done to avoid the influence of short story-assisted program on the researcher's performance in the control group. The researcher will, nevertheless, monitor the control group frequently.

After four weeks, students in both groups will take a Posttest. Points earned will be recorded for analysis. The percentile increase in the reading scores of Posttest will be compared to the Pretest percentile scores.

\section{Findings and Analysis}

The data obtained from the two instruments will be subjected to different statistical techniques, namely descriptive statistics and t-test.

The selection of the Pretest-Posttest Equivalent-Group Design allows the researcher to compare the gain scores of both the treatment and control groups and to test the significance of any differences between the means. The internal validity is good because between the pre and post tests no confounding variables exist. The external validity is good due to the selection of students using randomization.

The independent variables are the two groups and the dependent variable is the gain score from pretest to posttest. The pretest will be conducted at the beginning of the experiment and the score will be recorded. The posttest will be performed at the end of the experiment and the score will be documented. The gain score will be computed based on the percentile 
increase from pretest at the beginning to the posttest at the end of the experiment.

The hypothesis to be tested is that the short story-assisted program has a positive impact on the reading comprehension of eighth grade students. The results of this study will be analyzed with Pretest-Posttest Equivalent-Group Design.

The null hypothesis is that there is no difference in the gain scores of the control and treatment groups. The independent sample t-test will be used to examine the relationship between the control and treatment group's gain scores. If there is a significant gain, then the null hypothesis will be rejected. Related sample t-tests will be done for each group to test for significant improvement in each group.

Short story based quizzes and reports will be used by the treatment group's teacher for monitoring of adherence to the short story-assisted program instructions and to ensure student progress toward reading goals and advancement of reading levels.

\section{Conclusion and Recommendations}

The current study is expected to reveal that there will be an affirmative outcome of short story-assisted program on students' attitudes and comprehension. This implies that teachers and curriculum designers should perhaps use more students-centered methods of teaching that promote critical awareness in students and help them become more independent learners.

Consequently, literary texts, should not be reduced to exercises or drill, but ought to be permitted to exist as a piece of art, influencing the reader to see, think, feel as well as reflect.

Finally, curriculum designers should guide teachers into using more students-centered methods in the classroom and should encourage teachers into designing and using their own materials, which may better suit their students. EFL teachers should be trained to use the short story-assisted program. Inter schools workshops may be organized, the In-Service Training could be enhanced by Education Department and the research culture ought to be encouraged.

\section{References}

Al-Bulushi, A. (2011). Teaching Short Stories in the Omani Context: The Use of the Reader Response Theory. Literacy Information and Computer Education Journal (LICEJ), 2, 450-455.

Feldman, S. (2002). Focus on reading. American Teacher, 86, 5.

Howie, S. H. (1993). Critical thinking: A critical skill for students. Reading TODAY, 24.

Moats, L. (1999). Teaching reading is rocket science. Washington, DC: American Federation of Teachers.

Murdoch, G. (2002). Exploiting well-known short stories for language skills development. IATEFL LCS SIG Newsletter, 23, 9-17.

Young, A. (1996). Introducing critical thinking at the college level with children's stories. 


\begin{tabular}{rr} 
Macrothink & International Journal of English Language Education \\
Institute & ISSN 2325-0887 \\
IM & 2013, Vol. 1, No. 3 \\
\hline
\end{tabular}

College Teaching, 44(3), 90.

\section{Copyright Disclaimer}

Copyright reserved by the author(s).

This article is an open-access article distributed under the terms and conditions of the Creative Commons Attribution license (http://creativecommons.org/licenses/by/3.0/). 